\title{
Resistência de genótipos de batata ao vírus do enrolamento da folha da batata (PLRV) e ao vírus Y (PVY)
}

\author{
Julio Daniels; Arione da S. Pereira \\ Embrapa Clima Temperado, C. Postal 403, 96001-970 Pelotas-RS; E-mail: daniels@ cpact.embrapa.br
}

\begin{abstract}
RESUMO
O vírus do enrolamento da folha da batata (Potato leafroll virus, PLRV) e o vírus Y da batata (Potato virus $Y, \mathrm{PVY}$ ) constituem as principais causas da degenerescência da batata-semente no Brasil. Com o objetivo de determinar, nas condições do Rio Grande do Sul, a resistência de campo de genótipos de batata à infecção por estes vírus, avaliaram-se, na presença de infectores, durante três plantios consecutivos de primavera, 20 cultivares e clones de batata. A detecção dos vírus foi efetuada por meio de testes sorológicos (DASELISA). Pela análise de agrupamento os genótipos foram separados em três grupos para resistência ao PLRV (Elvira, Achat, Bintje, Monalisa, Monte Bonito, Panda e Araucária, resistentes; Baronesa, Asterix, Atlantic, 2CRI-1149-1-78, C-1226-35-80, Astrid, C-17147-94, A-1139-12-92, Macaca, Eliza e Santo Amor, suscetíveis; Catucha e Cristal, muito suscetíveis) e em quatro grupos para resistência ao PVY (Asterix, Astrid, Catucha, Cristal, Macaca, Monte Bonito, A-1139-12-92, C-1226-35-80 e C-1714-7-94, resistentes; Baronesa, Santo Amor, Monalisa, Panda e 2CRI-1149-1-78, resistentes intermediários; Bintje, Atlantic, Elvira e Araucária, suscetíveis; Achat e Eliza, muito suscetíveis).
\end{abstract}

Palavras-chave: Solanum tuberosum L., Potato leafroll virus, Potato virus $\mathrm{Y}$.

\begin{abstract}
Resistance of potato genotypes to Potato leafroll virus and to Potato virus $Y$

Potato leafroll virus (PLRV) and Potato virus Y (PVY) are the main causes of degeneration of potato seeds in Brazil. The field resistance of potato genotypes to these viruses was evaluated in Rio Grande do Sul State, Brazil, of 20 clones and cultivars, during three consecutive spring cropping seasons. Virus detection was carried out by serological tests (DAS-ELISA). Using the grouping analysis, the genotypes were separated in three groups for PLRV resistance (Elvira, Achat, Bintje, Monalisa, Monte Bonito, Panda and Araucária, resistant; Baronesa, Asterix, Atlantic, 2CRI-1149-1-78, C-1226-3580, Astrid, C-1714-7-94, A-1139-12-92, Macaca, Eliza and Santo Amor, susceptible; Catucha and Cristal, very susceptible) and in four groups for PVY resistance (Asterix, Astrid, Catucha, Cristal, Macaca, Monte Bonito, A-1139-12-92, C-1226-35-80 and C-1714-7-94, resistant; Baronesa, Santo Amor, Monalisa, Panda and 2CRI-11491-78, intermediate resistance; Bintje, Atlantic, Elvira and Araucária, susceptible; Achat and Eliza, very susceptible).
\end{abstract}

Keywords: Solanum tuberosum L., Potato leafroll virus, Potato virus Y.

(Recebido para publicação em 25 de outubro e 2003 e aceito em 19 de abril de 2004)

$\mathrm{P}$ ara que o cultivo de batata atinja alta produtividade, a sanidade das lavouras é fundamental. Nas principais regiões produtoras do país a batata-semente degenera muito rapidamente, exigindo freqüentes renovações dos tubérculos para o plantio, sendo que a principal razão dessa degeneração é a infecção por vírus, com destaque para o vírus do enrolamento da folha da batata (Potato leafroll virus, PLRV) e para o vírus $\mathrm{Y}$ da batata (Potato virus Y, PVY) (Daniels, 1995; Figueira, 1995; Souza Dias, 1995). Este fato eleva o custeio da lavoura de batata, pois o custo das 'sementes' representa 30 a $50 \%$ do seu valor. Além disso, a maioria dos produtores, principalmente os do segmento da agricultura familiar, não faz a renovação das 'sementes' com a frequiência necessária e planta tubérculos com altos índices de infecção por viroses, obtendo consequentemente baixa produtividade (Daniels, 2003).
Para o controle do PLRV, considerado o principal vírus da batata no Brasil, algumas medidas podem ser usadas, incluindo esquemas de certificação de batata-semente, métodos especiais de cultivo e controle dos vetores (Barker e Harrison, 1985). Em adição, deve-se plantar, preferencialmente, genótipos com algum grau de resistência, embora a efetividade dependa da pressão de infecção, que está relacionada com a abundância de fontes de inóculo (plantas infectadas pelo vírus) dentro da lavoura e/ou na região de cultivo, além da população e da atividade dos afídeos vetores.

Tentativas de desenvolver cultivares resistentes ao PLRV têm sido frustradas devido a dois fatores: 1) os genes que conferem resistência ao vírus são frequientemente ligados com caracteres indesejáveis, como formato irregular e tamanho pequeno de tubérculo, e baixa produtividade; 2 ) o controle genético da resistência é complexo, envolvendo diversos genes (Barker e Harrison, 1985).

A resistência ao PLRV é provavelmente controlada por genes menores, sendo, portanto, poligênica e expressa como uma resistência quantitativa. Três componentes da resistência podem ser encontrados em alguns genótipos: 1) restrição à multiplicação do vírus; 2) resistência à infecção; 3) inibição do movimento do vírus da folhagem para os tubérculos. O primeiro destes componentes é controlado por um gene dominante (Solomon-Blackburn e Barker, 1993).

A característica de resistência à infecção pelo PLRV tem sido estimada por meio de experimentos utilizando-se a exposição de genótipos em campo, sendo, portanto, demorada, dispendiosa e, muitas vezes, imprecisa, não fornecendo muita informação sobre os mecanismos de resistência envolvidos. Como a resistência à multiplicação do vírus está 
Tabela 1. Infecção de genótipos de batata pelo vírus do enrolamento da folha da batata (Potato leafroll virus - PLRV), após três plantios consecutivos de primavera, na presença de infectores. Embrapa Clima Temperado, Pelotas, 2002.

\begin{tabular}{|c|c|c|}
\hline Cultivar/Clone & Infecção p/PLRV ${ }^{1}$ & Grupo de resistência ${ }^{2}$ \\
\hline Catucha & $90 a^{3}$ & MS \\
\hline Cristal & $70 a b$ & MS \\
\hline Baronesa & $56 \mathrm{bc}$ & $S$ \\
\hline Asterix & $54 \mathrm{bc}$ & $S$ \\
\hline Atlantic & $54 \mathrm{bc}$ & $S$ \\
\hline 2CRI-1149-1-78 & $52 \mathrm{bc}$ & $S$ \\
\hline C-1226-35-80 & $51 \mathrm{bc}$ & $S$ \\
\hline Astrid & $50 \mathrm{bc}$ & $S$ \\
\hline C-1714-7-94 & $43 \mathrm{bc}$ & $S$ \\
\hline A-1139-12-92 & 37 & $S$ \\
\hline Macaca & $36 \quad c$ & $S$ \\
\hline Eliza & $32 \mathrm{~cd}$ & $S$ \\
\hline Santo Amor & 29 cde & $S$ \\
\hline Elvira & 25 cde & $\mathrm{R}$ \\
\hline Achat & de & $\mathrm{R}$ \\
\hline Bintje & 0 & $\mathrm{R}$ \\
\hline Monalisa & 0 & $\mathrm{R}$ \\
\hline Monte Bonito & 0 & $\mathrm{R}$ \\
\hline Panda & 0 & $\mathrm{R}$ \\
\hline Araucária & 0 & $\mathrm{R}$ \\
\hline
\end{tabular}

${ }^{1}$ Médias de quatro parcelas (dados transformados em arco seno da raiz quadrada de $\mathrm{X} / 100$ ). Detecção efetuada por DAS-ELISA, em cinco amostras por parcela, coletadas no final do ciclo de cultivo.

${ }^{2}$ Análise de agrupamento das cultivares e clones de batata para resistência à infecção pelo PLRV, conforme o método de Scott \& Knott (1974). MS = Muito suscetível; S = Suscetível; $\mathrm{R}=$ Resistente.

${ }^{3}$ Médias seguidas por letras distintas diferem entre si, ao nível de 5\% de probabilidade, pelo teste de Duncan.

associada com altas taxas de resistência em experimentos de campo, a sua avaliação, por meio de testes sorológicos quantitativos, tem sido também recomendada para acessar a resistência de genótipos de batata (SolomonBlackburn e Barker, 1993).

O PVY vem crescendo em importância nos estados de Minas Gerais (Figueira, 1995), de São Paulo (SouzaDias, 1995) e do Rio Grande do Sul (Daniels, 1996), onde a sua incidência era praticamente nula há cerca de vinte anos (Daniels e Castro, 1984). Atualmente, é possível que este vírus tenha superado o PLRV quanto aos prejuízos causados à bataticultura brasileira.

As estirpes de PVY podem ser divididas em três grupos principais, reconhecidos como $\mathrm{PVY}^{0}, \mathrm{PVY}^{\mathrm{N}}$ e PVYC As estirpes de $\mathrm{PVY}^{0}$, ou comuns, porque são mundialmente disseminadas, causam sintomas típicos em batata, in- cluindo mosaico, necrose das nervuras, senescência e queda das folhas. As estirpes de $\mathrm{PVY}^{\mathrm{N}}$, ou necróticas em fumo, são mais restritas na sua distribuição geográfica, e causam mosqueado leve nas folhas de batata, que passa muitas vezes despercebido aos erradicadores e certificadores de lavouras para produção de batata-semente. As estirpes de $\mathrm{PVY}^{\mathrm{C}}$ têm a sua distribuição mais reduzida do que os outros grupos citados e a sua caracterização é ambígua. Alguns isolados de $\mathrm{PVY}^{\mathrm{C}}$ causam reações de hipersensibilidade em cultivares de batata e outros não são transmissíveis por afídeos, fatores que limitam sua disseminação, influenciando a epidemiologia desta virose (Ellis et al., 1997). Porém, igualmente patogênicos, com perdas expressivas de produção.

A estirpe PVY ${ }^{\mathrm{NTN}}$, pertencente ao grupo $P V Y^{\mathrm{N}}$, tem causado grande preocupação entre produtores e técnicos que se dedicam ao cultivo de batata no país. Embora a sua incidência e distribuição ainda não tenham sido precisamente determinadas, foi recentemente detectada nos estados do Paraná, Minas Gerais e São Paulo (Souza-Dias et al., 1999). A sua diagnose é complicada porque, nem sempre, os tubérculos infectados mostram os sintomas característicos de lesões necróticas, o que permitiria a detecção do vírus através de inspeções visuais, aumentando os prejuízos com perdas de produção da batata nessas regiões.

A caracterização da maioria dos isolados de PVY é possível por meio de testes serológicos, utilizando-se de anticorpos monoclonais, porém, para as estirpes que são variantes dentro de um mesmo grupo, como é o caso da estirpe PVY ${ }^{\mathrm{NTN}}$, a detecção tem sido feita com a transcrição reversa de fragmento do genoma, seguida da reação em cadeia da polimerase (reverse transcriptionpolymerase chain reaction, RT-PCR).

A resistência ao PVY é baseada nos genes $N y$, de expressão variável e parecendo serem dependentes da estirpe do vírus, e no gene $R y$, que confere imunidade (Foxe, 1992).

O controle das viroses da batata no Brasil é dificultado pela ausência de invernos rigorosos, o que favorece a multiplicação dos afídeos vetores durante todo o ano e, especialmente, nas épocas propícias ao cultivo de batata. Como não se encontram no país regiões e épocas livres destes vetores, e como o seu combate através da aplicação de inseticidas, geralmente não é efetivo no controle das viroses em geral e principalmente do PVY, além de ser deletério ao meio ambiente, outras estratégias devem ser pesquisadas. Entre estas, destaca-se o uso de cultivares resistentes, potencialmente uma das mais efetivas e sustentáveis (Gallo et al., 1994).

Este trabalho foi realizado na Microrregião de Pelotas (RS) e teve como objetivo determinar a resistência relativa, também chamada de resistência de campo, de 20 cultivares e clones de batata, ao PLRV e ao PVY.

\section{MATERIAL E MÉTODOS}

Os tubérculos das cultivares e dos clones selecionados utilizados nesta 
pesquisa (Tabelas 1 e 2), isentos de infecção pelo PLRV e pelo PVY, foram obtidos na Embrapa Clima Temperado, Pelotas (RS), conforme tecnologia descrita por Costa et al. (1989) e Daniels (1994), multiplicados em áreas isoladas e armazenados por cerca de oito meses em câmara fria $\left(4^{\circ} \mathrm{C}, 85 \%\right.$ de umidade relativa), para equilíbrio do estado fisiológico. Como fonte de inóculo, foram utilizados tubérculos infectados obtidos em lavouras comerciais, realizando-se após testes de indexação e multiplicação em casa de vegetação e em campo, bem como de experimentos realizados previamente para testes de alguns genótipos (Daniels, 2000).

Foi utilizada a metodologia de Bagnall e Tai (1986a; 1986b) para a avaliação da resistência de campo de batata à infecção pelo PLRV e pelo PVY, com algumas modificações. Os experimentos foram instalados nos períodos de primavera (setembro a dezembro) nos anos 2000, 2001 e 2002, em campos da Embrapa Clima Temperado, em áreas isoladas entre si e de outros plantios de batata por vegetação natural e/ou por pomares de fruteiras. Cada parcela foi constituída por 20 tubérculos em uma linha de seis metros. O delineamento experimental foi inteiramente casualizado, com quatro repetições. Entre cada duas linhas de plantio, distanciadas de $80 \mathrm{~cm}$, e nas externas, foram plantados tubérculos infectados com PLRV e com PVY, respectivamente para cada experimento, que deram origem às plantas infectoras ou fontes de inóculo dos vírus. O plantio e o manejo dos experimentos foram efetuados conforme Bisognin (1996), com exceção do controle de pragas, que não foi efetuado, favorecendo-se a proliferação de insetos, inclusive dos afídeos vetores de vírus.

No final de cada ciclo de cultivo, foi efetuada uma amostragem das plantas, coletando-se, de cada parcela, uma folha central de cinco plantas aleatórias, para análise sorológica através de DASELISA (Clark e Adams, 1977), com reagentes (IgG e conjugado) específicos para detecção do PLRV (Loewe Biochemicals, Sauerlach, Alemanha) e do PVY (Daniels et al., 1987). Os tubérculos colhidos foram classificados e armazenados por cerca de oito meses em câmara fria $\left(4^{\circ} \mathrm{C}, 85 \%\right.$ de umidade relativa), para o plantio seguinte.

Tabela 2. Infecção de genótipos de batata pelo vírus Y (Potato virus $Y$ - PVY), após três plantios consecutivos de primavera, na presença de infectores. Embrapa Clima Temperado, Pelotas, RS, 2002.

\begin{tabular}{|c|c|c|}
\hline Cultivar/Clone & Infecção p/PLRV ${ }^{1}$ & Grupo de resistência ${ }^{2}$ \\
\hline Catucha & $90 a^{3}$ & MS \\
\hline Cristal & $70 a b$ & MS \\
\hline Baronesa & $56 \mathrm{bc}$ & $S$ \\
\hline Asterix & $54 \mathrm{bc}$ & $S$ \\
\hline Atlantic & $54 \mathrm{bc}$ & $S$ \\
\hline 2CRI-1149-1-78 & $52 \mathrm{bc}$ & $S$ \\
\hline C-1226-35-80 & $51 \mathrm{bc}$ & $S$ \\
\hline Astrid & $50 \mathrm{bc}$ & $S$ \\
\hline C-1714-7-94 & $43 \mathrm{bc}$ & $S$ \\
\hline A-1139-12-92 & $37 \quad c$ & $S$ \\
\hline Macaca & 36 & $S$ \\
\hline Eliza & 32 & $S$ \\
\hline Santo Amor & cde & $S$ \\
\hline Elvira & cde & $\mathrm{R}$ \\
\hline Achat & de & $\mathrm{R}$ \\
\hline Bintje & 0 & $\mathrm{R}$ \\
\hline Monalisa & e & $\mathrm{R}$ \\
\hline Monte Bonito & e & $\mathrm{R}$ \\
\hline Panda & 0 & $\mathrm{R}$ \\
\hline Araucária & 0 & $\mathrm{R}$ \\
\hline
\end{tabular}

${ }^{1}$ Médias de infecção de quatro parcelas (dados transformados em arco seno da raiz quadrada de X/100). Detecção efetuada por DAS-ELISA, em cinco amostras por parcela, coletadas no final do ciclo de cultivo.

${ }^{2}$ Análise de agrupamento das cultivares e clones de batata para resistência à infecção pelo PVY, conforme o método de Scott \& Knott (1974). MS = Muito suscetível; S = Suscetível; $\mathrm{RI}=$ Resistente intermediário; $\mathrm{R}=$ Resistente .

${ }^{3}$ Médias seguidas por letras distintas diferem entre si, ao nível de 5\% de probabilidade, pelo teste de Duncan.

A avaliação final foi efetuada nos percentuais de infecção detectados no terceiro ano de plantio, quando alguns dos genótipos atingiram o limite máximo de infecção (100\%). Para comparação dos genótipos usou-se a análise da variância dos percentuais de infecção, transformados em arco seno da raiz de $\mathrm{X} / 100$, e a análise de agrupamentos, conforme Scott e Knott (1974). Os genótipos foram agrupados em três extratos quanto a resistência ao PLRV [resistente (R), suscetível (S) e muito suscetível (MS)] e em quatro em relação ao PVY [resistente (R), resistente intermediário (RI), suscetível (S) e muito suscetível (MS)].

\section{RESULTADOS E DISCUSSÃO}

As cultivares e os clones testados comportaram-se da seguinte forma quanto à resistência ao PLRV: Elvira,
Achat, Bintje, Monalisa, Monte Bonito, Panda e Araucária, resistentes; Baronesa, Asterix, Atlantic, 2CRI-1149-178, C-1226-35-80, Astrid, C-1714-7-94, A-1139-12-92, Macaca, Eliza e Santo Amor, suscetíveis; e Catucha e Cristal, muito suscetíveis (Tabela 1).

As cultivares estrangeiras Asterix, Atlantic, Elvira, Bintje, Monalisa e Panda, que obtiveram na Europa, índices em relação a resistência ao PLRV $4^{1 / 2}$ e $5 ; 6 ; 6 ; 6$ e $6^{1 / 2} ; 8$; e 7 ; respectivamente, conforme classificação (NIVAA, 1991 e 1997; Swiezynskil et al., 2002), que varia de 9 (resistente) a 1 ou 2 (muito suscetível) comportaram-se, neste estudo, como suscetíveis as duas primeiras e as demais como resistentes, demonstrando-se compatibilização entre as avaliações. Porém, quando confrontadas as classificações deste trabalho com aquelas divulgadas por Reifschneider et al. (1989), em relação às cultivares Achat 
(R e S), Baronesa (S e RI), Bintje (R e S), Elvira (R e RI), Monalisa (R e RI) e Santo Amor (S e RI), os resultados foram discrepantes.

As cultivares e os clones testados reagiram da seguinte forma quanto à resistência ao PVY: Asterix, C-1226-3580, Monte Bonito, A-1139-12-92, Macaca, Astrid, Cristal, Catucha e C1714-7-94, resistentes; Baronesa, Santo Amor, Monalisa, Panda e 2CRI-11491-78, resistentes intermediários; Bintje, Atlantic, Elvira e Araucária, suscetíveis; e Eliza e Achat, muito suscetíveis (Tabela 2).

As cultivares estrangeiras Elvira, Atlantic, Bintje, Panda, Monalisa e Asterix, que obtiveram na Europa, índices em relação a resistência ao PVY de $8 ; 3 ; 5$ e $5^{1 / 2} ; 8 ; 9 ; 5^{1 / 2}$ e 6 , respectivamente, conforme classificação (NIVAA, 1991 e 1997; Swiezynskil et al., 2002), que varia de 9 (resistente) a 1 ou 2 (muito suscetível) comportaram-se, neste estudo, como suscetíveis as três primeiras, como resistentes intermediárias as duas seguintes, e como resistente a última, demonstrando-se discrepâncias entre as avaliações. O mesmo aconteceu, quando foram confrontadas as classificações obtidas neste trabalho com aquelas divulgadas por Reifschneider et al. (1989), em relação às cultivares Achat (MS e R) e Elvira (S e R).

Conforme Solomon-Blackburn e Barker (1993), a comparação de resultados destes tipos de experimentos é difícil, porque a pressão de infecção varia entre diferentes locais e entre diferentes épocas. Inconsistências na comparação de dados de avaliação da resistência de campo à viroses, de alguns genótipos de batata, em diferentes anos, foram reportadas por Gallo et al. (1994). Não obstante, é possível que as diferenças observadas na comparação dos dados deste trabalho em relação a outros, sejam, também, devidas aos métodos utilizados para avaliação da incidência de infecção. Alguns genótipos podem mostrar somente sintomas fracos, difíceis de serem reconhecidos sem o auxí- lio de testes sorológicos. Portanto, em experimentos de campo em que a taxa de infecção é avaliada visualmente, é possível que a informação obtida não seja correta.

\section{AGRADECIMENTOS}

Os autores agradecem aos colegas Vera Osório, pela análise estatística, Claiton Amaral Kuhn e José Idalino do Amaral, pelo apoio técnico na execução dos experimentos de campo e nos testes sorológicos, respectivamente.

\section{LITERATURA CITADA}

BAGNALL, R.H.; TAI, G.C.C. Field resistance to potato virus $\mathrm{Y}$ in potato assessed by cluster analysis. Plant Disease, v.70, n.4, p.301-304, 1986a.

BAGNALL, R.H.; TAI, G.C.C. Potato leafroll virus: evaluation of resistance in potato cultivars. Plant Disease, v.70, n.7, p.621-623, 1986b.

BARKER, H.; HARRISON, B.D. Restricted multiplication of potato leafroll virus in resistant potato genotypes. Annals of Applied Biology, v.107, p.205-212, 1985.

BISOGNIN, D.A. (Coord.). Recomendações técnicas para o cultivo da batata no Rio Grande do Sul e Santa Catarina. Santa Maria: Universidade Federal de Santa Maria, 1996. 64 p.

CLARK, M.F.; ADAMS, A.N. Characteristics of the microplate method of enzyme-linked immunosorbent assay (ELISA) for the detection of plant viruses. Journal of General Virology, v.34, p.475-483, 1977.

COSTA, D.M.; CASTRO, L.A.S.; PETERS, J.A.

Batata: a busca de maior produtividade. Horti Sul, Pelotas, v.1, n.0, p.40-42, 1989.

DANIELS, J. Produção de batata-semente no Rio Grande do Sul. Horti Sul, Pelotas, v.3, n.1, p.1215, 1994.

DANIELS, J. Viroses da batata e suas implicações na produção de batata-semente no Rio Grande do Sul. Summa Phytopathologica, Piracicaba, v.21, n.3-4, p.269-270, 1995.

DANIELS, J. Incidência do vírus Y da batata (PVY) em lavouras e em lotes de tubérculos-semente de produtores de São Joaquim, SC e de Bom Jesus, RS, no período 1995/6. In: REUNIÃO TÉCNICA ANUAL DE PESQUISA E EXTENSÃO DA CULTURA DA BATATA NO RIO GRANDE DO SUL E SANTA CATARINA, 3., 1996, Santa Maria, RS. Anais ... Santa Maria, RS, 1996. p. 40. (Resumo).

DANIELS, J. Avaliação de genótipos de batata para resistência ao vírus Y. Horticultura Brasileira, Brasília, v.18, n.2, p.145-147, 2000.
DANIELS, J. Batata-semente para uso próprio. In: Pereira, A.S. \& Daniels, J. (Eds.) O cultivo da batata na Região Sul do Brasil. Embrapa Informação Tecnológica, Brasília. 2003. p. 495-508. DANIELS, J.; CASTRO, L.A.S. Incidência de viroses em lavouras de batata do Rio Grande do Sul. Fitopatologia Brasileira, Brasília, v.9, p.398, 1984. (Resumo 178).

DANIELS, J.; CASTRO, L.A.S.; PAIVA, E.; KULCZYNSKI, S.M. Obtenção e utilização de anti-soro para diagnose do vírus $Y$ da batata. Pelotas: EMBRAPA-CNPFT, 1987. 15 p. (EMBRAPA-CNPFT. Boletim de Pesquisa, 14). ELLIS, P.; STACE-SMITH, R.; VILLIERS, G. Identification and geographic distribution of serotypes of potato virus Y. Plant Disease, v.81, n.5, p.481-484, 1997.

FIGUEIRA, A.R. Viroses da batata e suas implicações na produção de batata-semente no estado de Minas Gerais: histórico do problema e soluções. Summa Phytopathologica, Piracicaba, v.21, n.3-4, p.268-269, 1995.

FOXE, M.J. Breeding for viral resistance: conventional methods. Netherlands Journal of Plant Pathology, v.98, Suppl. 2, p.13-20, 1992.

GALLO, L. G.; SLACK, S.A.; LORIA, R. An approach to field screening potato genotypes for potato leaf roll virus resistance. American Potato Journal, v.71, n.1, p.115-125, 1994.

NIVAA. Catálogo Holandês de Variedades de Batata. Haarlem, Holanda: Boom-Ruygrok, 1991. 230 p.

NIVAA. Catálogo Holandês de Variedades de Batata. Haarlem, Holanda: Boom-Planeta B. V., 1997. 270 p.

REIFSCHNEIDER, F.J.B.; LOPES, C.A.; COBBE, R.V. Manejo integrado das doenças de batata. Brasília: EMBRAPA Hortaliças, 1989. 16 p. (EMBRAPA Hortaliças. Circular Técnica, 7). SCOTT, A.J.; KNOTT, M. A cluster analysis method for grouping means in the analysis of variance. Biometrics, v.30, p.507-512, 1974.

SOLOMON-BLACKBURN, R.M.; BARKER, H. Resistance to potato leaf roll luteovirus can be greatly improved by combining two independent types of heritable resistance. Annals of Applied Biology, n.122, p.329-336, 1993.

SOUZA-DIAS, J.A.C. Viroses da batata e suas implicações na produção de batata-semente no estado de São Paulo. Summa Phytopathologica, Piracicaba, v.21, n.3-4, p.264-266, 1995.

SOUZA-DIAS, J.A.C.; MIRANDA FILHO, H.S.; GRANJA, N.P.; HAYASHI, P. Novas observações sobre a putativa raça NTN do vírus Y da batata (PVY NTN), causadora de anéis necróticos superficiais nos tubérculos. In: CONGRESSO PAULISTA DE FITOPATOLOGIA, 22., Jaboticabal, 1999. Anais... Jaboticabal: UNESP, 1999. p.105. (Resumo 106).

SWIEZYNSKIL, K.M.; SIECZKA, M.T.; STYPA, I.; ZIMNOCH-GUZOWSKA, E. Characteristics of major potato varieties from Europe and North America. Disponível em: http:/ www.ihar.edu.pl/gene-bank/potato, new/potato, html. 2002. 